\title{
Shifting Focus of Primary Health Care in the Context of Health Systems Reform in Resource Poor Settings
}

\section{GA Nnaji*}

Department of Community Medicine and Primary Health Care, Faculty of Medicine, College of Health Sciences, Nnamdi Azikiwe University, Nnewi Campus, Nigeria

\author{
Abstract \\ Purpose: To review the concepts of Primary Health Care (PHC) and provide evidence for a shift in its focus and \\ implementation in the resource poor setting.
}

Sources of data: Desk and internet based review of relevant articles and official documents.

Data extraction: Search themes were 'concepts and models of PHC', contextual issues in PHC and health care reforms aimed at achieving the universally accepted core social values of health care delivery.

Results: Four main concepts and approaches to $\mathrm{PHC}$ include selective $\mathrm{PHC}$, primary care; Alma-Ata comprehensive $\mathrm{PHC}$ and health and human rights approach. The concept of PHC in resource poor settings is oversimplified and restrictive. This is in contrast with the situation in well-resourced contexts where primary care concept is practiced. The World Health Organisation recommends a shift in focus of PHC through four sets of reforms in the health system, universal coverage reforms, service delivery reforms, public policy reforms and leadership reforms. This shift should bridge the gap between citizens' expectations and performance of the health care system.

Conclusion: Inability of health services to deliver levels of national coverage that meet stated demands and changing needs has been a source of worry. The health systems need to respond better and faster to the challenges of a changing world.

Keywords: Primary care; Primary health care; Universal coverage; Health reforms; Social protection

\section{Introduction}

The Alma-Ata conference, held about thirty years ago resulted in a paradigm shift in the thinking about health and this eventually led to the mobilization of the "PHC movement" of professionals, institutions, governments, civil society organizations, researchers and grassroots organizations [1]. The movement aimed at resolving the "politically, socially and economically unacceptable" health inequalities in all countries. The Alma-Ata declaration focused on a set of values to be pursued such as social justice and the right to better health for all, participation and solidarity [2,3]. Health systems development has been devoid of equity and social justice and has failed to get the best health outcomes for citizens' money. Currently, three trends have characterized the health system; focusing disproportionately on a narrow offer of specialized curative care; using a command-andcontrol approach to disease control with focus on short term results and fragmenting service delivery; a laissez-faire approach to governance, which has allowed unregulated commercialization of health to flourish [1].

Globally, there has been a noticeable rise in social expectation among the citizens on health care, and attempts are being made to ensure that "their voice and choice decisively influence the way in which health services are designed and operated"[4-6]. In a recent PHC review by the Pan American Health Organisation, this perspective became clearer as the "right to the highest attainable level of health", "maximizing equity and solidarity" while being guided by "responsiveness to people's needs" [7]. The health systems should respond to the challenges of a changing world and growing expectations for better performance if the goal of health for all would ever be achieved.

The five common short comings of the health care system, especially in resource poor settings include the following; first, Inverse care, public spending on health services tend to benefit the rich more than the poor [8] in high- and low income countries alike [9-10].
The rich people, whose needs for health care are often less, consume the most care, whereas those at lower socio-economic level with the greatest health problems consume the least [11]. Secondly, impoverishing care, where health expenses are paid out-of-pocket by people who do not have social protection, which may lead to impoverishment [12]. Thirdly, fragmented and fragmenting care, which is a feature of excessive specialization by health-care providers and narrow focus of many disease control programmes, which discourage a holistic approach to health care and need for continuity of care [13]. Health services for the poor are often highly fragmented and severely under-resourced [14,15]. Fourthly, unsafe care, results from poor system design leading to lower safety and hygiene standards, high rates of hospital-acquired infections, and medication errors [16]. Finally, misdirected care, in which more resources are being allocated to curative services, neglecting the primary prevention and health promotion which contribute up to $70 \%$ of the disease burden in communities [17].

There is need therefore for a thorough understanding of the PHC concepts and models in order to understand the basis for paradigm shift.

The concept of PHC has undergone tremendous over simplification in resource poor settings, e.g. sub Saharan Africa [1]. In well-resourced contexts, however, primary care is described in the context of physicians

*Corresponding author: Godswill Amechi Nnaji, Department of Family Medicine, Nnamdi Azikiwe University Teaching Hospital, PMB 5025, Nnewi, Anambra State, Nigeria, E-mail: godswilln@yahoo.co.uk

Received November 03, 2011; Accepted December 02, 2011; Published December 08, 2011

Citation: Nnaji GA (2011) Shifting Focus of Primary Health Care in the Context of Health Systems Reform in Resource Poor Settings. Primary Health Care: Open Access 1:102. doi:10.4172/2167-1079.1000102

Copyright: () 2011 Nnaji GA. This is an open-access article distributed under the terms of the Creative Commons Attribution License, which permits unrestricted use, distribution, and reproduction in any medium, provided the original author and source are credited. 
in family medicine or general practice specialty. This concept contrasts sharply with the restrictive and poorly conceptualized primary care recipes used in resource poor settings.

The purpose of this paper is to review the concepts of PHC and to provide evidence for a shift in its focus and implementation in resource poor settings. In addition, the paper examines the contextual issues in $\mathrm{PHC}$ as well as the recommended health care reforms for adoption in resource poor settings.

\section{Methods}

Literature search of Medline using Ovid and Pubmed for all papers focusing on concepts in primary health care in developing and developed countries' settings which were published since 1970 was carried out. The first search theme used was concepts and models of PHC with sub-theme as - essential criteria of PHC. The second search theme was contextual issues in PHC with a sub-theme of types of health facilities, and changing role of doctors, assessment of quality of care, and medical education. The third theme was health care reforms aimed at achieving the universally accepted core social values of health care delivery. Studies concerning primary care concepts of individual diseases were excluded, and searches were limited to concepts on which nations organised and evaluated their health care systems. Abstracts were reviewed individually to identify potentially relevant papers, while the full papers were reviewed to select those included in this paper. Subsequently, references to these papers were searched by hand to identify additional publications. Other sources used were libraries and some official government documents and reports.

Three reviews papers, two reports and 32 descriptive papers on conceptual and contextual issues as well as health care reforms were found and represent the work by the author. No quantitative data was included in this survey.

\section{Results and Discussion}

In order to achieve the PHC value of health for all, the health system must "put people at the centre of health care" [19]. Currently, the dominant paradigm is curative medicine, while the PHC paradigm assumes that a diversified health care team should use modern technology and resources to anticipate and promote well being [20].

\section{Concepts and models of PHC}

Two papers saw PHC strategy as an innovative idea that provoked contradictory views and wide differences in interpretation [21]. They reported that the deviations of conceptual content and practice of PHC lead to the concept of selective PHC that is practiced in resource poor countries [21]. Others insist that the divergent views are a product of the ambitious and somewhat vague descriptions of PHC as contained in the Alma-Ata declaration [22]. This argument tended to portray the differences in the conceptualization of $\mathrm{PHC}$ as being inherent in the descriptions.

Fourteen papers were reviewed on conceptual theoretical paradigm of PHC as being implemented globally. Four main models of PHC have been described, which include the selective PHC, Primary care concept, comprehensive PHC and health and human rights concept [23]. The first model was described as selective PHC concept which focuses on a limited number of high-impact services to address some of the most prevalent health challenges in developing countries [24]. The main services include GOBI (growth monitoring, oral rehydration techniques, breastfeeding, and immunization) or where food supplementation, female literacy, and family planning are included GOBI-FFF. This concept emphasized specific set of health service activities directed towards the poor. Most resource poor countries including Nigeria hold this concept of PHC.

The second model is the primary care concept which refers to the entry point into the health system that provide continuing health care for most people, most of the time. This concept and approach to PHC is common in Europe and other industrialized countries. The approach depends on the availability of practicing physicians in general practice or family medicine specialty. It represents a level of care in a health care system [25-27].

A third concept encountered during the search was Alma-Ata 'comprehensive PHC' concept, which defines PHC as the first level of care that is integrated and comprehensive. It includes elements of community participation, inter-sectoral collaboration and reliance on a variety of health workers and traditional practitioners. This concept includes several principles: the need to address wider health determinants; universal accessibility and coverage on the basis of need; community and individual involvement and self reliance; inter sectoral action for health; and appropriate technology and cost effectiveness in relation to available resources [28-31].

Finally, the fourth concept identified was the health and human right concept, which views health as a human right with the need to tackle the broader social and political determinants of health [32]. It advocates that the social and political focus of PHC should be emphasized more than disease-specific aspects [33]. Some papers noted that, although all countries agree on the principles underlying PHC, they differ greatly in their approach to implementation and management of PHC [34-35]. They found that in the resource poor countries, oversimplification of the PHC message by the PHC movement resulted in the adoption of the one-size-fit all recipes, which is ill adapted to different contexts and problems [28]. Consequently, national and global health authorities have tended to see PHC not as a reform strategy but as a health care delivery programme among many, providing poor care for poor people [1]. It has been argued that a shift in PHC focus will provide a sense of direction to the health system, and nations are required to apply a set of specific and context sensitive reforms that respond to challenges of today, while preparing for those of tomorrow [36].

The essential criteria of PHC include accessibility, equity, social justice and protection, improved first contact with the health care system, decentralization of the existing health system, without neglecting the quality of care on higher-level medical services [21].

\section{Historical context in PHC}

Nine papers dwelt on the historical context in which PHC is being introduced. It was observed that many developing countries inherited colonial infrastructures with imbedded values, perceptions, expectations, administration, which may require radical change [34]. Hospitals constitute a very important element of the health care system and they present many challenges to policy makers undertaking reform of health care systems. Hospitals account for about $50 \%$ of overall health care expenditure in most countries, dominating the rest of the health care system and being viewed by the public as the main manifestation of the health care system [37]. In South Africa communities are first classified as "developed" or "developing" areas. These communities require different methods of PHC provision depending on their level of development. It is argued that because problems, priorities and resources are not the same in both communities they can not have 
same health service [38]. The day hospital and large comprehensive health centres are gaining support as ideal facilities for delivering PHC, especially in urban areas [39]. In South Africa, first-contact primary care is delivered by nurses in small clinics and larger community health centres (CHC) [40]. In china, the government decided to develop a PHC system rather than to promote a system of specialized health care for a small segment of the population [41]. Also, the government established a universal, compulsory financial system for health care [42].

Two articles reviewed concluded that there is need for the doctors' roles to change in line with the principles of primary health care with the implication of expanding service coverage to rural communities. The authors stated that doctors should not only be competent clinicians but also good managers of health promotive and preventive programmes, effective hospital administrators, competent trainers and qualified researchers. The doctor should be able to perform three functions in the PHC system, i.e. consultation, supervision, and training [43]. Adequate knowledge and appropriate skills in supporting PHC at the community level are a prerequisite of a district doctor.

The challenges in resource poor settings are that graduates of traditional medical schools are not adequately equipped for the emerging new roles for doctors in rural hospitals. There is need for reorientation of the existing health system to be able to achieve this. The critical factor in this process of change is the development of appropriate attitudes at all levels of health services. This change involves long established medical institutions which hold firmly to old traditions and values.

Urgent issues for consideration by those involved in the preparation of the curriculum of medical education is the role of the physician in a PHC system and how medical schools can best prepare their prospective graduates for this role in a developing country [44].

Two articles were reviewed on quality of care, both treated quality as relationship issues. This is referred to as patient centeredness [45]. Trust, mindfulness, heedfulness, respectful interaction, diversity, social/task relatedness, and rich/lean communication were identified as important in practice improvement [46]. These were considered to be the core features of patient centeredness. The organisation for economic cooperation and development OECD member countries are more detailed when they make reference to quality of care and they expand the features to include the following dimensions; acceptability, accessibility, appropriateness, capacity, competence or capability, continuity, effectiveness or improved health or clinical focus, efficiency, equity, patient centeredness, or patient focus, or responsiveness, safety, sustainability and timeliness [47-48]. Four papers were reviewed on the adequacy of the medical education of doctors. The authors agreed that the traditional system of medical education did not prepare doctors adequately in developing countries for their expected leadership role in meeting the health needs for their communities through primary health care [49-50]. This is in spite of the acknowledgement and adoption of the Alma-Ata declaration by majority of the countries of the world as a strategy for achieving health for all [51]. Changes in medical education must accompany changes in structure, content and organisation of health services so that health professionals will not find it difficult to function as team leaders in the health care system. There is need for a reorientation of physician training toward primary health care, increasing the quality of existing health services, and ensuring more efficient management of resources [52].

\section{Health care reforms}

Five papers were reviewed on health care reforms in developing countries. One of the papers showed that in Ghana, health care reforms involved changing to a 3-tier health system made up of level $\mathrm{A}$, the community level; level B, the local council subareas; and level C, the district [53]. In Cameroon, obstacles to primary health care include low priority in the country's budget and over-all policy [54]. It has been argued that the goal of equality of health status may not be appropriate in many developing country situations. Instead it has been suggested that a stepwise approach based on progressive redistribution of medical services and resources may be more appropriate as goal [55]. In Thailand, health care system incorporates the private and public sectors. The government regulates health care, protects its interests while providing a climate for competition. Consequently, the private sector has developed and implemented some concepts in health care, neighbourhood-based ambulatory care and home care [56]. In one of the 36 states in Nigeria, Enugu state, the district health system (DHS) was introduced as a structural means of integrating primary and secondary health care services with a functional referral system in the State. Consequently, the health reform law of 2005 assigned the functions of providing policy development, structural reforms, creating integrating structures, decentralization of control, universal access to health care for all citizens, effective referral system (these are assumed and not emphasized in the developed countries' concept of health system) among levels of health care [57]. The law provides for the strengthening of the health system by emphasizing integrated monitoring, supervision and support by levels of component structures of the DHS. The public private providers were to be involved in the DHS.

\section{Recommended conceptual shift by world health organisation}

The review of the World Health Report 2008, on the current concerns on PHC showed a remarkable shift in paradigm [2]. The focus is shifting from access to a basic health package interventions and essential drugs for the rural poor to total transformation and regulation of existing health systems for universal access and social health protection. The focus on maternal and child health is shifting to the all inclusive concept of dealing with the health of everyone in the community. The focus on caring for small number of selected diseases, especially infectious and acute illnesses has shifted to a comprehensive response to people's expectations and needs, and covering all risks and illnesses [2]. The focus on improvement of hygiene, water, sanitation and health education at village level is shifting to the promotion of healthier lifestyles and mitigation of the health effects of social and environmental hazards. Simple technology for volunteer, nonprofessional community health workers shifts to teams of health workers facilitating access to and appropriate use of technology and medicines. There is need for a shift from the participation as the mobilization of local resources and health-centre management through local health committees to the institutionalized participation of civil society in policy dialogue and accountability mechanisms. Government-funded and delivered services with a centralized top-down management should be replaced with pluralistic health systems operating in a globalized context. The focus on management of growing scarcity and downsizing should shift to guiding the growth of resources for health towards universal coverage. The focus on bilateral aid and technical assistance should shift to global solidarity and joint learning, while that of primary care as the antithesis of the hospital shift to Primary care as coordinator of a comprehensive response at all levels. Finally, the 
concept of PHC being cheap and requiring only a modest investment should be dropped in favour of PHC not being cheap and requiring considerable investment, but it provides better value for money than its alternatives.

\section{Recommended health care reforms by WHO}

The review of WHO's recommended reforms revealed four sets of reforms [2].

The four sets of reforms necessary to refocus the health system to achieve the objective of health for all (HFA) include universal coverage, service delivery, public policy and leadership reforms. Universal coverage reforms deals with equity, social justice and the end of exclusion in the health system, primarily by moving towards universal access and social health protection. Service delivery reforms is a component of health system reforms, which reorganizes health services as primary care, focusing on people's needs and expectations, so as to make them more socially relevant and more responsive to the changing world while producing better outcomes. Public policy reforms deals with policy making reforms and aims at securing healthier communities, by integrating public health actions with primary care and by pursuing healthy public policies across sectors. Leadership reforms replace disproportionate reliance on command and control and laissez-faire by state with an inclusive, participatory, negotiation-based leadership, which is required by the complexity of contemporary health systems.

\section{Recommended shift in PHC conceptual theoretical framework}

According to the World health report of 2008, Primary care should provide a platform for people to bring a wide range of health problems. This is in contrast with what obtains in low-income countries where primary care deals with a few "priority diseases". Primary care should be the hub/ compass on which patients are guided through the health system, however, in low-income countries, primary care has been reduced to a stand-alone health post or isolated community-health worker [1].

Primary care sets the stage for the ongoing relationships between patients and clinicians, and offers a platform for the patients to participate in decision-making about their health and health care. It should provide the link between personal health care and patients' families and communities; however, this is different in low-income countries, where primary care is restricted to a one-way delivery channel for priority health interventions [1].

Primary care should offer opportunities for disease prevention, health promotion and early detection of disease, in contrast with what obtains in low-income countries, where primary care is all about treating common ailments. In developed economies, primary care requires teams of health professionals such as physicians, nurse practitioners, and assistants with specific and sophisticated biomedical and social skills, whereas in low-income countries, primary care is synonymous with low-technology and non-professional care for the rural poor.

Primary care requires adequate funding to enable it provide much better value for money than its alternatives rather than what obtains in low-income countries, where primary care is funded through out-ofpocket payments on the erroneous assumption that it is cheap and the poor should be able to afford it.

\section{Conclusion}

The four main models of PHC include the selective PHC, primary care concept, comprehensive PHC and health and human rights concept. Countries differ greatly in their approach to implementation and management of PHC. The PHC concept and implementation should be context sensitive in order to address the citizens' needs and expectations. There is need for the doctors' roles to change with regards to the expanding service coverage to rural communities. The doctor should be able to perform three critical functions in the PHC system, i.e. consultation, supervision, and training. The deficiency of the traditional system of medical education in preparing doctors for their expected leadership role in primary health care has been emphasized. The adoption of the WHO's recommended shift in the focus of PHC as well as the implementation of health reforms remains the panacea for achieving the objective of health for all.

\section{References}

1. Primary health care: report of the International Conference on Primary Health Care, Alma-Ata, USSR (1978) jointly sponsored by the World Health Organization and the United Nations Children's Fund. Geneva, World Health Organization (Health for All Series No. 1).

2. World Health Report 2008 - Primay Health Care- now more than ever, WHO.

3. The Ljubljana Charter on Reforming Health Care (1996) World Health Organization Regional Office for Europe, Copenhagen.

4. Saltman R, Rico A, Boerma W (2006) Primary health care in the driver's seat organizational reform in European primary care. European Observatory on Health Systems and Policies Series, Maidenhead, England, Open University Press.

5. Report on the review of primary care in the African Region (2003) World Health Organization Regional Office for Africa, Brazzaville.

6. International Conference on Primary Health Care (2003) Alma-Ata: twenty-fi fth anniversary, World Health Organization, Geneva.

7. Renewing primary health care in the Americas: a position paper of the Pan American Health Organization (2007) Pan American Health Organization, Washington DC

8. World development report 2004: making services work for poor people. The World Bank, 2003, Washington DC.

9. Filmer D (2003) The incidence of public expenditures on health and education. Washington DC, The World Bank, (background note for World development report 2004 - making services work for poor people).

10. Hanratty B, Zhang T, Whitehead M (2007) How close have universal health systems come to achieving equity in use of curative services? A systematic review. International Journal of Health Services 37: 89-109.

11. Hart T (1971) The inverse care law. Lancet 1:405-412.

12. Xu K, Evans DB, Carrin G, Aguilar-Rivera AM, Musgrove P (2007) Protecting households from catastrophic health expenditures. Health Affairs 6: 972-983.

13. Starfield B (2002) Policy relevant determinants of health: an international perspective. Health Policy 60: 201-218.

14. Moore G, Showstack J (2003) Primary care medicine in crisis: towards reconstruction and renewal. Annals of Internal Medicine 138: 244-247.

15. Shiffman J (2008) Has donor prioritization of HIVIAIDS displaced aid for other health issues. Health Policy and Planning 23: 95-100.

16. Kohn LT, Corrigan JM, Donaldson MS (1999) To err is human: building a safer health system. Committee on Quality of Care in America, Institute of Medicine, National Academy Press, Washington DC.

17. Fries JF, Koop E, Beadle CE, Cooper PP, England MJ, et al. (1993) Reducing health care costs by reducing the need and demand for medical services. New England Journal of Medicine 329: 321-325. 
Citation: Nnaji GA (2011) Shifting Focus of Primary Health Care in the Context of Health Systems Reform in Resource Poor Settings. Primary Health Care: Open Access 1:102. doi:10.4172/2167-1079.1000102

Page 5 of 5

18. The World Health Report 2002-Reducing risks, promoting healthy life (2002) World Health Organization, Geneva.

19. WHO Regional Office for South-East Asia and WHO Regional Office for the Western Pacific (2007) People at the centre of health care: harmonizing mind and body, people and systems. World Health Organization, Geneva

20. Frenk J, González-Block MA, Alvarez-Manilla JM (1990) First contact, simplified technology, or risk anticipation? Defining primary health care. Acad Med 65: 676-681.

21. Grodos D, de Béthune $X$ (1988) Selective health systems: a trap for health politics in the third world. Soc Sci Med 26: 879-889.

22. Tejada de Rivero D (2003) Alma-Ata Revisited. Perspectives in Health 8: 2-7.

23. Renewing primary health care in the Americas: a position paper of the Pan American Health Organization/WHO. Draft for discussion.

24. Walsh JA, Warren KS (1979) Selective primary health care: an interim strategy for disease control in developing countries. N Engl J Med 301: 967-974.

25. Defining primary care: an interim report (1994) Institute of Medicine, National Academy Press, Washington DC.

26. Boerma W, Fleming D (1998) The role of general practice in primary health care. Norwich: The Stationery Office/World Health Organization Regional Office for Europe.

27. Weiner JP (1987) Primary care delivery in the United States and four northwest European countries: comparing the "corporatized" with the "socialized". The Milbank Quarterly 65: 426-461.

28. Tarimo E, Webster EG (1997) Primary health care concepts and challenges in a changing world. Alma-Ata revisited. (Current Concerns ARA paper number 7 , document WHO/ARA/CC/97.1) Geneva: WHO.

29. World Health Organization (2003) Chapter 7: Health Systems: principled integrated care. In: WHO, editor, World Health Report 2003, Geneva: WHO.

30. A Global Review of Primary Health Care: Emerging Messages (2003) World Health Organization, Geneva: WHO.

31. World Health Organization (2004) Multi-country Evaluation of IMCI: Main Findings: WHO.

32. People's Health Movement (2003) Health for All Now! Revive Alma-Ata!! The Alma-Ata Anniversary Pack, Unnikrishnan, Bangalore, India.

33. People's Health Movement (2000) The Medicalization of Health Care and the challenge of Health for all. People's Health Assembly, Dhaka, Bangladesh.

34. Vaughan JP, Walt G (1984) Implementing primary health care: some problems of creating national programmes. Trop Doct 14: 108-113.

35. Spencer IW (1983) Primary health care provision in terms of community need in South Africa. Isr J Med Sci 19: 703-706.

36. Blendon RJ (2002) Inequities in health care: a five-country survey. Health Affairs 21: 182-191.

37. McKee M, Healy J (2000) The role of the hospital in a changing environment. Bulletin of the World Health Organization 78: 803-810

38. Spencer IW (1983) Primary health care provision in terms of community need in South Africa. Isr J Med Sci 19: 703-706.

39. Botha HP (1983) Primary health care according to African requirements. Isr J Med Sci 19: 698-702.

40. Mash BJ, Mayers P, Conradie H, Orayn A, Kuiper M, et al. (2008) How to manage organisational change and create practice teams: experiences of a South African primary care health centre. Educ Health (Abingdon) 21: 132

41. Taylor RB (1981) Primary health care in the People's Republic of China. Postgrad Med 70: 69-76.

42. Hsiao WC (1984) Transformation of health care in China. N Engl J Med 310: 932-936.

43. Piyaratn $P$ (1982) Doctors' roles in primary health care. Trop Doct 12: 196-202.

44. Waterston A (1982) The doctor and the primary health worker. Trop Doct 12 : 101-103.
45. Lanham HJ, McDaniel RR Jr, Crabtree BF, Miller WL, Stange KC, et al. (2009) How improving practice relationships among clinicians and non clinicians can improve quality in primary care. Jt Comm J Qual Patient Saf 9: 457-466.

46. Saha S, Beach MC, Cooper LA (2008) Patient centeredness, cultural competence and healthcare quality. J Natl Med Assoc 100: 1275-1285.

47. Onyebuchi AA, Gert PW, Jeremy H, Niek SK (2006) A conceptual framework for the OECD Health Care Quality Indicators Project. International Journal for Quality in Health Care 1: 5-13.

48. Campbell SM, Roland MO, Buetow SA (2000) Defining quality of care. Soc Sci Med 51: 1611-1625.

49. Klevens J, Valderrama C, Restrepo O, Vargas P, Casasbuenas M, et al. (1992) Teaching community oriented primary care in a traditional medical school: a two year progress report. J Community Health 17: 231-245.

50. Akpala CO (1991) Medical education and primary health care in Nigeria: the Sokoto University experience. Cent Afr J Med 37: 374-377.

51. Bryant JH, Zuberi RW, Thaver IH (1991) Alma-Ata and health for all by the year 2000. The roles of academic institutions. Infect Dis Clin North Am 5: 403-416.

52. Hodes RM, Kloos H (1988) Health and medical care in Ethiopia. N Engl J Med 319: 918-924.

53. Nimo KP (1984) Health manpower planning for primary care in Ghana. Chin Med J 97: 97-100.

54. Van der Geest S (1982) The secondary importance of primary health care in South Cameroon. Cult Med Psychiatry 6: 365-383.

55. Low A, Ithindi T (2003) A step too far? Making health equity interventions in Namibia more sufficient. Int J Equity Health 2: 5.

56. Schwartz S (1993) Health care lessons from Thailand. Leadersh Health Serv 2: $20-24$.

57. Enugu State of Nigeria (2005) No 6 The Enugu State Health Law 2005. 